\title{
Synthesis of $\mathrm{BiF}_{3}$ and $\mathrm{BiF}_{3}-$ Added Plaster of Paris Composites for Photocatalytic Applications
}

\author{
V. P. Singh ${ }^{1,2,+}$, Mirgender Kumar ${ }^{3,+}{ }^{+}$, Moolchand Sharma ${ }^{1} \mathbb{D}$, Deepika Mishra ${ }^{4}$, Kwang-Su Seong $^{3}$, \\ Si-Hyun Park ${ }^{3, *}$ (D) and Rahul Vaish ${ }^{1, *}$ \\ 1 School of Engineering, Indian Institute of Technology Mandi, Suran 175005, HP, India; \\ vinay.phy@gmail.com (V.P.S.); sharma.moolchand09@gmail.com (M.S.) \\ 2 Department of Physics, Government Engineering College, Bharatpur 321001, RJ, India \\ 3 Department of Electronics Engineering, Yeungnam University, Gyeongsan 38541, Korea; \\ mkumar@ynu.ac.kr (M.K.); kssung@ynu.ac.kr (K.-S.S.) \\ 4 Department of Physics, Sri Satya Sai University of Technology \& Medical Sciences, Sehore 466001, MP, India; \\ vinay.matsci@ymail.com \\ * Correspondence: sihyun_park@ynu.ac.kr (S.-H.P.); rahul@iitmandi.ac.in (R.V.) \\ + First and second authors are equally contributed.
}

check for updates

Citation: Singh, V.P.; Kumar, M.;

Sharma, M.; Mishra, D.; Seong, K.-S.; Park, S.-H.; Vaish, R. Synthesis of $\mathrm{BiF}_{3}$ and $\mathrm{BiF}_{3}$-Added Plaster of Paris Composites for Photocatalytic Applications. Energies 2021, 14, 5159. https://doi.org/10.3390/en14165159

Academic Editor: Wasim Khan

Received: 29 June 2021

Accepted: 14 August 2021

Published: 20 August 2021

Publisher's Note: MDPI stays neutral with regard to jurisdictional claims in published maps and institutional affiliations.

Copyright: (c) 2021 by the authors. Licensee MDPI, Basel, Switzerland. This article is an open access article distributed under the terms and conditions of the Creative Commons Attribution (CC BY) license (https:// creativecommons.org/licenses/by/ $4.0 /)$.

\begin{abstract}
A} \mathrm{BiF}_{3}$ powder sample was prepared from the purchased $\mathrm{Bi}_{2} \mathrm{O}_{3}$ powder via the precipitation route. The photocatalytic performance of the prepared $\mathrm{BiF}_{3}$ powder was compared with the $\mathrm{Bi}_{2} \mathrm{O}_{3}$ powder and recognized as superior. The prepared $\mathrm{BiF}_{3}$ powder sample was added in a plaster of Paris (POP) matrix in the proportion of $0 \%, 1 \%, 5 \%$, and $10 \%$ by $w \mathrm{t} \%$ to form $\mathrm{POP}-\mathrm{BiF}_{3}(0 \%)$, $\mathrm{POP}-\mathrm{BiF}_{3}(1 \%), \mathrm{POP}-\mathrm{BiF}_{3}(5 \%)$, and $\mathrm{POP}-\mathrm{BiF}_{3}(10 \%)$ composite pellets, respectively, and activated the photocatalytic property under the UV-light irradiation,in the POP. In this work, Resazurin (Rz) ink was utilized as an indicator to examine the photocatalytic activity and self-cleaning performance of POP $-\mathrm{BiF}_{3}(0 \%), \mathrm{POP}-\mathrm{BiF}_{3}(1 \%), \mathrm{POP}-\mathrm{BiF}_{3}(5 \%)$, and $\mathrm{POP}-\mathrm{BiF}_{3}(10 \%)$ composite pellets. In addition to the digital photographic method, the UV-visible absorption technique was adopted to quantify the rate of the de-colorization of the $\mathrm{Rz}$ ink, which is a direct measure of comparative photocatalytic performance of samples.
\end{abstract}

Keywords: $\mathrm{BiF}_{3}$ nanostructure; POP composite; photocatalyst; $\mathrm{Rz}$ ink

\section{Introduction}

Recent development has focused on creating newly sustainable, low-cost photocatalytic materials with a superior performance than the traditional semiconductor photocatalysts such as $\mathrm{TiO}_{2}$ and $\mathrm{ZnO}$ for self-cleaning applications [1]. In this direction, a huge potential is observed for the Bi-based semiconductors and their complexes [2-11]. This group of materials possess a direct band gap of a wide range from $2.5 \mathrm{eV}$ to $3.2 \mathrm{eV}$ and is severally reported for the fast rate of the creation of photo-induced charge carriers $[12,13]$. Moreover, most of all the Bi-based compounds show layered structures with polar surfaces and are found responsible for accelerating the separation of photo-generated carriers; consequently, reducing the recombination efficiency and showing a better photocatalytic activity even under the exposure of low intensity of light irradiation [13-17]. Among them, $\mathrm{Bi}_{2} \mathrm{O}_{3}$ has been studied extensively and found to be superior photocatalytic, highly photoconductive, and nontoxic in nature, having a narrow band gap of about $2.8 \mathrm{eV}[15,16,18]$. $\mathrm{Bi}_{2} \mathrm{O}_{3}$ has four kinds of polymorphs which are designated as $\alpha$ for the monoclinic structure, $\beta$ for the tetragonal structure, $\gamma$ for the body-centered cubic structure, and $\delta$ is for the face-centered cubic structure $[19,20]$. In several cases, $\mathrm{Bi}_{2} \mathrm{O}_{3}$ has been reported for dye degradation, the photosynthesis of organic compounds, and water splitting for hydrogen generation [21-23]. To enhance the photocatalytic performance further, the structure and the surfaces of the $\mathrm{Bi}_{2} \mathrm{O}_{3}$ compound are tailored extensively. For example, the $\beta$ phase of 
$\mathrm{Bi}_{2} \mathrm{O}_{3}$ is doped with $\mathrm{Ti}$, which improves the photocatalytic activity comparatively [24]. In some cases, $\mathrm{Bi}_{2} \mathrm{O}_{3}$ has been further modified to form $\mathrm{Bi}_{2} \mathrm{O}_{3}$-based complexes with several other materials to create heterojunctions, which further supported the creation and separation of the photo-induced charge carriers in the heterointerface [25-28]. In previous reports, Singh et al. demonstrated the modification of $\mathrm{Bi}_{2} \mathrm{O}_{3}$ or Bi-based compounds through halogenations which lead to the formation of $\mathrm{BiOCl}$ and $\mathrm{BiOF}$ compounds, respectively, with a huge advancement in photocatalytic and self-cleaning properties [29,30].

Similarly, in the present work, $\mathrm{Bi}_{2} \mathrm{O}_{3}$ powder is used as the initial material and processed further with HF treatment and completely modified into the $\beta$ phase of $\mathrm{BiF}_{3}$. Usually, $\mathrm{BiF}_{3}$ exists in two structures, cubic and orthorhombic, depicted as the $\alpha$ phase and $\beta$ phase, respectively [31]. The $\alpha$ phase of $\mathrm{BiF}_{3}$ and its applications are reported most commonly for simple synthesis methods and low cost with high photo-activity [32-34]. In a reported research work by Chenkai Feng et al., the $\alpha$ phase of the $\mathrm{BiF}_{3}$ sample is prepared and then the photocatalytic performance is compared with the commercially available $\mathrm{TiO}_{2}$ powder sample [32]. Interestingly, the $\alpha$ phase of $\mathrm{BiF}_{3}$ is found 2.1 times superior to the $\mathrm{TiO}_{2}$ powder sample [32]. However, the preparation and applications of $\mathrm{BiF}_{3}$ having $\beta$ phase are less explored. Therefore, in this work, after the preparation of the $\beta$ phase of $\mathrm{BiF}_{3}$, we analyzed its photocatalytic property and compared it with the initially purchased $\mathrm{Bi}_{2} \mathrm{O}_{3}$ powder. In order to explore the possible utilization of $\mathrm{BiF}_{3}$ for commercial application, it is important to look into a sustainable strategy. One of the methods could be in composite paints and coatings. $\mathrm{BiF}_{3}$ can be physically mixed with any well-known and widely used materials, such as cement-based paints and other ceramic coatings. Plaster of Paris is known for the aesthetics and decoration material. It is also used in medicine to make casts for broken bones. To explore photocatalysis-based effects in plaster of Paris, it may be used for air cleaning as well as antibacterial properties. Hence, $\mathrm{BiF}_{3}$ embedded in a plaster of Paris (POP) matrix is fabricated by varying the $\mathrm{BiF}_{3}$ amounts from $0 \%$ to $10 \mathrm{wt} \%$. Further, these POP- $\mathrm{BiF}_{3}(\%)$ compositions are tested for the photocatalytic response on Resazurin (Rz) ink. Rz ink is used as a prototype carcinogenic pollutant and an indicator of photocatalytic performance.

\section{Materials and Methods}

In the process of making $\mathrm{POP}-\mathrm{BiF}_{3}(\%)$ composites, first, we prepared the powder of the $\mathrm{BiF}_{3}$ sample. We obtained a precipitation technique to prepare the $\mathrm{BiF}_{3}$ sample. The fixed amount (5 g) of pure $\mathrm{Bi}_{2} \mathrm{O}_{3}$ powder of AR grade (Hi-media, $\geq 99 \%$ ) was dissolved in the hydrofluoric (HF) acid (Qualikems $40 \%$, Vadodara, India) solution $(30 \mathrm{~mL}$ ) and stirred for $30 \mathrm{~min}$. Under the stirring with $\mathrm{HF}$ solution, the yellow color of $\mathrm{Bi}_{2} \mathrm{O}_{3}$ gradually changed into white-color powder. The product of white powder was washed in distilled water several times followed by acetone and dried at $80^{\circ} \mathrm{C}$ for $24 \mathrm{~h}$ in a vacuum oven. A fraction of the sample was collected for testing, named sample $\mathrm{Bi}_{2} \mathrm{O}_{3}-\mathrm{HF}-1$. Again, the remaining product of white powder of $\mathrm{Bi}_{2} \mathrm{O}_{3}-\mathrm{HF}-1$ sample was dissolved in the concentrated HF solution and stirred for $30 \mathrm{~min}$. The output product obtained after the second treatment from HF solution was followed with the same procedures of washing, filtering, and drying as for the sample $\mathrm{Bi}_{2} \mathrm{O}_{3}-\mathrm{HF}-1$, and we procured the test sample2 named as sample $\mathrm{Bi}_{2} \mathrm{O}_{3}-\mathrm{HF}-2$. Similarly, a test sample3 was procured and named as sample $\mathrm{Bi}_{2} \mathrm{O}_{3}-\mathrm{HF}-3$ for further testing.

Next, by using the $\mathrm{Bi}_{2} \mathrm{O}_{3}-\mathrm{HF}-3$ powder sample, we prepared $\mathrm{POP}-\mathrm{BiF}_{3}(\%)$ composite pellets. In the composites, we maintained the concentration of $\mathrm{Bi}_{2} \mathrm{O}_{3}-\mathrm{HF}-3$ powder in the POP matrix in accordance with $0,1,5$, and $10 \mathrm{by} \mathrm{wt} \%$. With respect to each composition of POP- $\mathrm{BiF}_{3}(\%)$ composites, the calculated amount of $\mathrm{Bi}_{2} \mathrm{O}_{3}-\mathrm{HF}-3$ powder sample and POP were mixed rigorously to prepare a homogeneous mixture, separately. The paste of each mixture of different $\mathrm{POP}-\mathrm{BiF}_{3}(\%)$ composites was obtained by adding an equal amount of distilled water. Individually, the paste of different $\mathrm{POP}-\mathrm{BiF}_{3}(\%)$ composites was transferred into cylindrical molds of $20 \mathrm{~mm}$ diameter and $10 \mathrm{~mm}$ height to prepare the pellets of each composition, respectively. Finally, the pellets were left to naturally dry fortwo days. 
The structural analysis of $\mathrm{Bi}_{2} \mathrm{O}_{3}$, HF-treated $\mathrm{Bi}_{2} \mathrm{O}_{3}$ test samples, and $\mathrm{POP}-\mathrm{BiF}_{3}(\%)$ composite pellets was performed through X-ray diffraction (XRD) (Rigaku), having $9 \mathrm{~kW}$ rotating anode and $\mathrm{Cu} \mathrm{K} \alpha$ source. Microstructure analysis was obtained from FE-SEM (Inspect ${ }^{\mathrm{TM} S 50)}$. Optical property and photocatalytic performance were tested via UVvisible spectrophotometer of double beam (Thermo Scientific, Evolution 220, Waltham, MA, USA). In addition, to carry out the photocatalytic reaction, we used a box inbuilt with a lamp (Hitachi FL8BL-Blight) as a UV light source having maximum emission $~ 355 \mathrm{~nm}$ wavelengths. The distance between the lamps and the samples was adjusted such that the intensity falling on the samples was maintained at about 3200 lx.

\section{Results and Discussion}

The systematic XRD results of $\mathrm{Bi}_{2} \mathrm{O}_{3}$ and the samples obtained from the successive fluorination of $\mathrm{Bi}_{2} \mathrm{O}_{3}$ via $\mathrm{HF}$ solution are shown in Figure 1. The step-wise fluorinated samples are denoted as $\mathrm{Bi}_{2} \mathrm{O}_{3}-\mathrm{HF}-1, \mathrm{Bi}_{2} \mathrm{O}_{3}-\mathrm{HF}-2$, and $\mathrm{Bi}_{2} \mathrm{O}_{3}-\mathrm{HF}-3$, respectively. XRD of the purchased $\mathrm{Bi}_{2} \mathrm{O}_{3}$ sample was compared with the JCPDS file no 76-1730 and matched with the monoclinic phase. XRD results of the $\mathrm{Bi}_{2} \mathrm{O}_{3}-\mathrm{HF}-1$ sample revealed that after the 1st washing of $\mathrm{Bi}_{2} \mathrm{O}_{3}$ powder, new diffraction peaks appeared in the $\mathrm{X}$-ray diffraction pattern. A set of these new diffraction peaks was related to the intermediate phase of $\mathrm{Bi}_{1.2} \mathrm{~F}_{2.4} \mathrm{O}_{0.6}(\mathrm{PDF}-36-0457)$, which are marked as ${ }^{\prime \prime \prime}$. The other set of remaining peaks with less intensity belongs to the orthorhombic structure of $\mathrm{BiF}_{3}$ (PDF-70-2407). XRD results of the $\mathrm{Bi}_{2} \mathrm{O}_{3}-\mathrm{HF}-2$ sample for a 2 nd consecutive washing of the $\mathrm{Bi}_{2} \mathrm{O}_{3}$ powder showed the relative increase in the intensity of diffraction peaks belonging to the $\mathrm{BiF}_{3}$ (PDF-70-2407) phase structure at the expense of the diffraction peaks belonging to an intermediate phase of $\mathrm{Bi}_{1.2} \mathrm{~F}_{2.4} \mathrm{O}_{0.6}$ (PDF-36-0457), relatively. The almost pure phase of $\mathrm{BiF}_{3}$ (PDF-70-2407) appeared after the 3 rd consecutive washing of $\mathrm{Bi}_{2} \mathrm{O}_{3}$ powder in addition to a very small quantity of an unidentified impure phase which is marked as '\#'. Thus, multiple washing of $\mathrm{Bi}_{2} \mathrm{O}_{3}$ powder through the concentrated $\mathrm{HF}$ solution led towards the formation of the almost pure orthorhombic structure of the $\mathrm{BiF}_{3}$ powder sample.

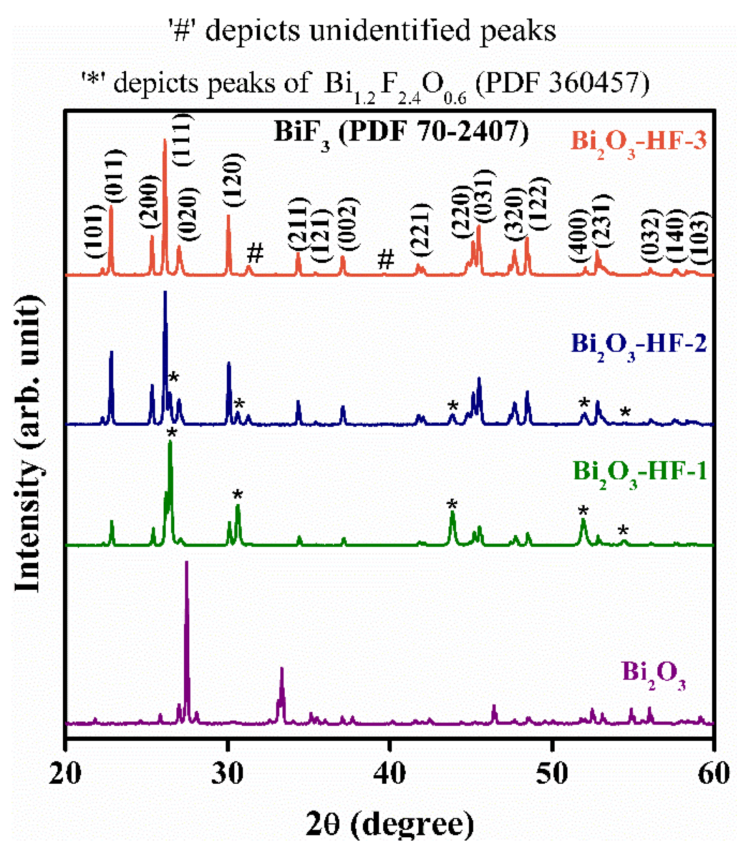

Figure 1. X-ray diffraction patterns of purchased $\mathrm{Bi}_{2} \mathrm{O}_{3}$ and $\mathrm{Bi}_{2} \mathrm{O}_{3}$ after three successive $\mathrm{HF}$ treatments depicted as $\mathrm{Bi}_{2} \mathrm{O}_{3}-\mathrm{HF}-1, \mathrm{Bi}_{2} \mathrm{O}_{3}-\mathrm{HF}-2, \mathrm{Bi}_{2} \mathrm{O}_{3}-\mathrm{HF}-3$, and $\mathrm{Bi}_{2} \mathrm{O}_{3}-\mathrm{HF}-4$, respectively.

Only a few solution techniques have been used for the formations of various phases of the $\mathrm{BiF}_{3}$ sample through different methods. For example, Feng et al. reported the formation of $\mathrm{BiF}_{3}$ (JCPDS: 51-0944) by a simple water-bath method, where they kept the molar ratio of 
$\mathrm{Bi}$ and $\mathrm{F}$ above 1:3, otherwise the impurity of $\mathrm{Bi}_{2} \mathrm{O}_{3}$ and $\mathrm{BiOF}$ remained present [32]. In this method, the constituent of $\mathrm{Bi}$ was obtained from $\mathrm{Bi}_{2} \mathrm{O}_{3}$ while the element of $\mathrm{F}$ was attained from the $\mathrm{NH}_{4} \mathrm{~F}$ solution [32]. Zhao et al. reported the evolution of the $\mathrm{BiF}_{3}$ nanocrystals in various shapes from monodispersed nano-plates to nano-rods and then to nanowires via the novel acid-base couple extraction route and tuning the molar ratio of F vs. Bi [31]. Sarkar et al. used Poly (vinyl pyrrolidone) (PVP) for the encapsulation and formation of cubic nanocrystals of $\mathrm{BiF}_{3}$ via the hydrothermal method [35]. In another method, by using a novel ion-exchange approach, Kan et al. produced pure $\mathrm{BiF}_{3}$ (JCPDS: 73-1988). Here, the $\mathrm{NH}_{4} \mathrm{~F}$ solution was used for the constituent of $\mathrm{F}$ while $\mathrm{BiOCl}$ was utilized to attain the element of $\mathrm{Bi}$ in accordance with the molar ratio $(\mathrm{RF}=\mathrm{F} / \mathrm{Bi})$ of 8:1 [36]. Below to the molar ratio of 8:1 (RF), the final product consisted of a small amount of $\mathrm{Bi}_{7} \mathrm{~F}_{11} \mathrm{O}_{5}$ as an impurity phase [36].

Contrary to the above reported studies, in the present method, the ratio of $\mathrm{O} / \mathrm{F}$ was controlled via a chemical bath of $\mathrm{Bi}_{2} \mathrm{O}_{3}$ in a concentrated HF solution. The constituent of $\mathrm{Bi}$ was extracted from the powder of $\mathrm{Bi}_{2} \mathrm{O}_{3}$, while for the element of $\mathrm{F}$ in a concentrated HF solution was utilized. $\mathrm{Bi}_{2} \mathrm{O}_{3}$ powder was washed several times from the concentrated HF solution, which may have led to two types of products, as follows in the reaction mechanisms one and two given below:

$$
\begin{gathered}
2 \mathrm{Bi}^{3+}+6 \mathrm{~F}^{-} \rightarrow 2 \mathrm{BiF}_{3} \rightarrow(\text { Concentrated HF }) \\
2 \mathrm{Bi}^{3+}+2 \mathrm{H}_{2} \mathrm{O}+6 \mathrm{~F}^{-} \rightarrow 2 \mathrm{BiOF} \downarrow+4 \mathrm{HF} \text { (Diluted HF) }
\end{gathered}
$$

Multiple washing from HF solution increased the constituent of $\mathrm{F}$ and led towards the formation of $\mathrm{BiF}_{3}$ from $\mathrm{Bi}_{2} \mathrm{O}_{3}$ powder. Normally, if the $\mathrm{Bi}_{2} \mathrm{O}_{3}$ powder is washed from the concentrated $\mathrm{HF}$ solution, the positively charge $\mathrm{Bi}^{3+}$ ion reacts with $\mathrm{F}^{-}$ion and forms $\mathrm{BiF}_{3}$ and follows reaction mechanism one. However, in the HF solution, some water content always remains present; therefore, in the case of the 1st washing, some of the $\mathrm{Bi}_{2} \mathrm{O}_{3}$ powder converted into $\mathrm{BiF}_{3}$ according to reaction mechanism one, while some of the $\mathrm{Bi}_{2} \mathrm{O}_{3}$ powder reacted with $\mathrm{HF}$ as well as the water content, followed reaction mechanism 2 and formed an intermediate product of the BiOF family, which was recognized as $\mathrm{BiO}_{0.51} \mathrm{~F}_{1.98}$ in the present case. Further, the 2 nd and 3rd washing provided more and more $\mathrm{F}^{-}$ion in the solution which again reacted with the intermediate product of $\mathrm{BiO}_{0.51} \mathrm{~F}_{1.98}$ and converted it to the final product of the $\mathrm{BiF}_{3}$ sample. Multiple washing and high concentrations of $\mathrm{HF}$ increased the $\mathrm{F}$ concentration in the $\mathrm{O} / \mathrm{F}$ ratio and led toward the cubic- $\alpha \mathrm{BiF}_{3}$ phase (PDF-073-1988) from the $\mathrm{Bi}_{2} \mathrm{O}_{3}$ powder.

Further, the $\mathrm{BiF}_{3}$ powder was investigated for its photocatalytic performance and compared with the $\mathrm{Bi}_{2} \mathrm{O}_{3}$ powder sample. A total of0.05 g powder of both $\mathrm{Bi}_{2} \mathrm{O}_{3}$ and $\mathrm{BiF}_{3}$ were sonicated in $50-50 \mathrm{~mL}$ water solutions of the hazardous dye of Methylene blue $(\mathrm{MB})$, separately, as test solutions. Before the photocatalytic investigation of $\mathrm{Bi}_{2} \mathrm{O}_{3}$ and $\mathrm{BiF}_{3}$ samples, to neglect the effect of the adsorption-desorption of the dye over the surfaces of these powders, first both the test solutions of $\mathrm{Bi}_{2} \mathrm{O}_{3}$ and $\mathrm{BiF}_{3}$ in $\mathrm{MB}$ were sonicated under dark for a 30 min duration to achieve the adsorption-desorption equilibrium. Then, both the test solutions were transferred under the UV light irradiation of a $355 \mathrm{~nm}$ wavelength. To probe the photocatalytic activity of the $\mathrm{Bi}_{2} \mathrm{O}_{3}$ and $\mathrm{BiF}_{3}$ powder samples, $1-1 \mathrm{~mL}$ of the $\mathrm{MB}$ was collected in a separate Eppendorf from both the test solutions at fixed time intervals. Finally, the absorption study of the collected samples was carried out by using a UV-visible spectrophotometer. After the fixed time of reaction, both the solutions were sonicated for five minutes to maintain the homogeneity and, then, 1-1 mL of the MB was collected. Each collected sample was centrifuged to remove the segregated residual from the solutions. At last, the photocatalytic decomposition of MB for each collected sample from both the set of solutions immersed with $\mathrm{Bi}_{2} \mathrm{O}_{3}$ and $\mathrm{BiF}_{3}$ powders were tested from UV-visible spectroscopy, respectively.

The adsorption-desorption reaction analysis for both the samples under the dark environment showed an insignificant change in the concentration of MB solutions (absorbance 
results probed by UV-visible spectroscopy is not shown here). After adsorption-desorption, the photolysis and photocatalytic results of decomposition, as well as the kinetic rate of the decomposition of MB solutions under UV exposure, were plotted and represented in Figure $2 \mathrm{a}-\mathrm{c}$. The decomposition of the MB solution probed via absorbance data of UV-visible spectroscopy confirmed a fast degradation of $\mathrm{MB}$ solution for the $\mathrm{BiF}_{3}$ powder sample as compared to the $\mathrm{Bi}_{2} \mathrm{O}_{3}$ powder. For comparison purposes, and to remove the artifacts during the photocatalytic reaction, the photolysis of the blank MB solution was obtained for the same parameters and for the same time scale as maintained for the photocatalytic decomposition of $\mathrm{MB}$ solutions for the $\mathrm{Bi}_{2} \mathrm{O}_{3}$ and $\mathrm{BiF}_{3}$ powder samples. A control reaction of photolysis of blank $\mathrm{MB}$ solution under the exposure of $355 \mathrm{~nm}$ light radiation showed a negligible change in the concentration. In Figure 2d,e, the Co stands for initial concentration, while $\mathrm{Ct}$ represents the time-dependent concentration of the MB solution after the photocatalytic decomposition. Using the parameters $\mathrm{Co}$ and $\mathrm{Ct}$ and their relation with time, i.e., $\ln (\mathrm{C} / \mathrm{Co})=\mathrm{k}_{\mathrm{f}} \mathrm{t}$, the decomposition rate constant of $\mathrm{MB}$ solutions due to the photocatalytic reaction for both the powder samples were calculated and compared. Here, $\mathrm{k}_{\mathrm{f}}$ represents the rate constant of photocatalytic reactions, which was calculated as 0.0011 and $0.0103 \mathrm{~min}^{-1}$ for the $\mathrm{Bi}_{2} \mathrm{O}_{3}$ and $\mathrm{BiF}_{3}$ powders, respectively. Thus, the photocatalytic degradation of the $\mathrm{BiF}_{3}$ powder sample was confirmed to be multiple times higher than the $\mathrm{Bi}_{2} \mathrm{O}_{3}$ powder sample. A comprehensive study of photocatalysis is shown in Table 1.
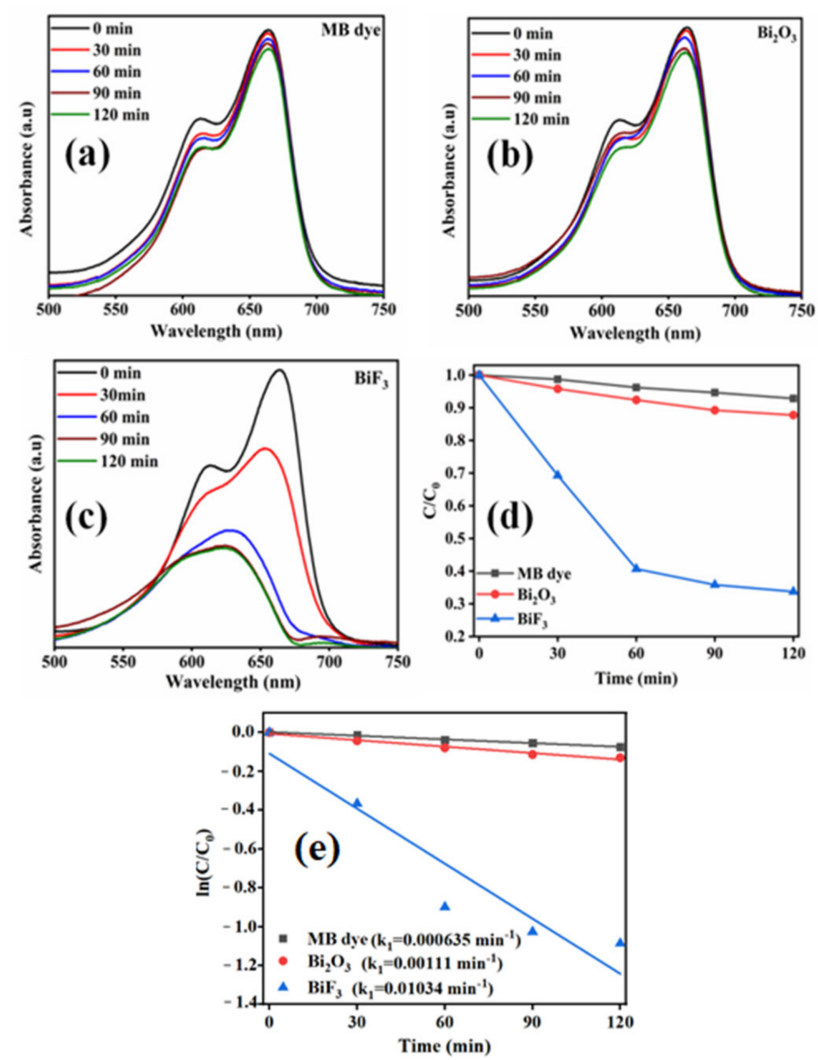

Figure 2. Absorption vs. wavelength spectra for (a) the photolysis of Methylene blue (MB), and the photocatalysis of MB under the exposure of UV light of $355 \mathrm{~nm}$ wavelength due to (b) $\mathrm{Bi}_{2} \mathrm{O}_{3}$ powder and (c) $\mathrm{BiF}_{3}$ powder $(\mathbf{d})$ respective $\mathrm{C} / \mathrm{Co}$ vs. time plots, and $(\mathbf{e}) \ln (\mathrm{C} / \mathrm{Co})$ vs. time plots to obtain the pseudo-first-order reaction rate constant for the photolysis of $\mathrm{MB}$ and the photocatalysis of $\mathrm{MB}$.

Four different composite pellets of $\mathrm{POP}-\mathrm{BiF}_{3}(\%)$ were obtained. The $\mathrm{BiF}_{3}$ power was varied in the POP matrix in accordance with $0,1,5$, and $10 \mathrm{by} \mathrm{wt} \%$. Here, the pellets of POP- $\mathrm{BiF}_{3}(\%)$ composites were named as POP- $\mathrm{BiF}_{3}(0 \%), \mathrm{POP}-\mathrm{BiF}_{3}(1 \%), \mathrm{POP}-\mathrm{BiF}_{3}(5 \%)$, and $\mathrm{POP}-\mathrm{BiF}_{3}(10 \%)$, respectively. The composite formation and purity of $\mathrm{POP}-\mathrm{BiF}_{3}(0 \%)$, 
POP- $-\mathrm{BiF}_{3}(1 \%), \mathrm{POP}-\mathrm{BiF}_{3}(5 \%)$, and $\mathrm{POP}-\mathrm{BiF}_{3}(10 \%)$ pellets were checked and verified through XRD (not shown here).

Again, the absorption of UV-visible radiation for $\mathrm{POP}-\mathrm{BiF}_{3}(0 \%), \mathrm{POP}-\mathrm{BiF}_{3}(1 \%), \mathrm{POP}-$ $\mathrm{BiF}_{3}(5 \%)$, and $\mathrm{POP}-\mathrm{BiF}_{3}(10 \%)$ pellets was probed and utilized for the bandgap calculations according to the Kubelka-Munk model [37]. Results are shown in Figure 3a,b. Figure 3a demonstrates the gradual increase in the absorption from the visible to UV region for the POP sample. Adding $\mathrm{BiF}_{3}$ in the POP matrix improved the absorption towards the visible range, relatively. The results of the absorption coefficient $(\alpha)$ vs. incident photon energy $\mathrm{E}$ $(\mathrm{h} v)$ obtained from Figure 3a were extrapolated according to the Kubelka-Munk model to calculate the direct bandgap of $\mathrm{POP}$ and $\mathrm{POP}-\mathrm{BiF}_{3}(\%)$ composites, as shown in Figure $3 \mathrm{~b}$. Results showed that the bandgap tended to decrease with the addition of $\mathrm{BiF}_{3}$ in the POP matrix from $3.69 \mathrm{eV}$ to $3.26 \mathrm{eV}$, respectively.
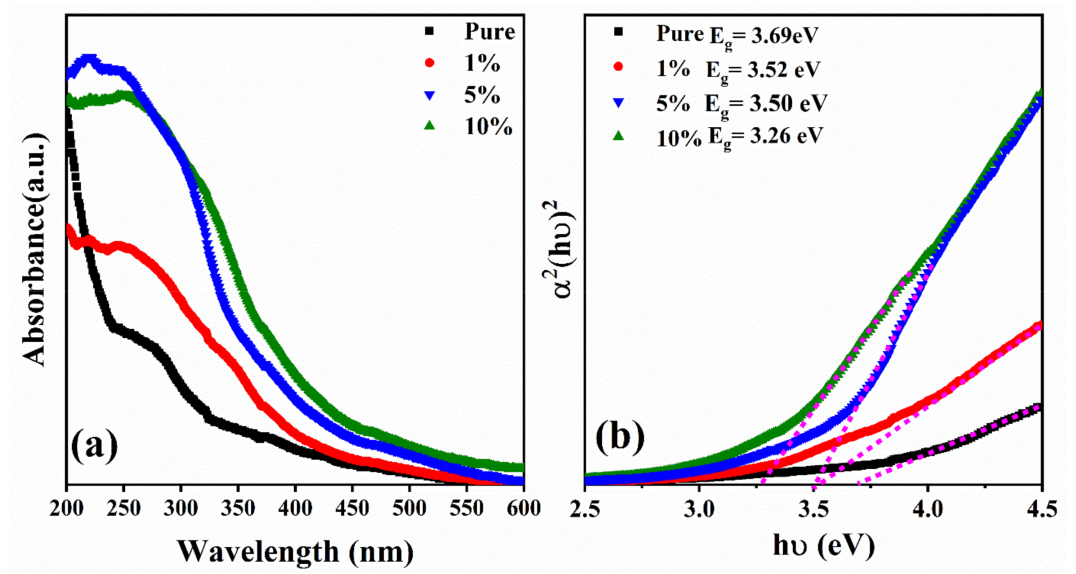

Figure 3. (a) Absorption spectra and (b) $\alpha^{2}(\mathrm{~h} v)^{2}$ vs. hv plots for the band gap (E $\left.\mathrm{E}_{\mathrm{g}}\right)$ calculation of $\mathrm{POP}-\mathrm{BiF}_{3}(\%)$ composites with the variation of $\mathrm{BiF}_{3}$ concentration $0 \%, 1 \%, 5 \%$, and $10 \%$ in POP matrix.

The variation in morphology of the POP- $\mathrm{BiF}_{3}(\%)$ composite pellets along with the change of $\mathrm{BiF}_{3}$ concentration in the POP matrix were probed through SEM and are shown in Figure $4 \mathrm{a}-\mathrm{d}$. The surface image of $\mathrm{POP}-\mathrm{BiF}_{3}(0 \%)$ pellet stands for the pure POP sample and shows a homogeneous rod-shape microstructure. These rods were entangled with each other and made net-like porous surfaces. One end of the rod was defused in the surface while the other end seemed to emerge from the surface and dangle. Such entangled rods over the surface of the $\mathrm{POP}-\mathrm{BiF}_{3}(0 \%)$ pellet were due to water treatment and the continuous hydration of POP which led to the continuous nucleation and growth of rods in random orientations. SEM images of the $\mathrm{BiF}_{3}$-added $\mathrm{POP}-\mathrm{BiF}_{3}(0 \%), \mathrm{POP}-\mathrm{BiF}_{3}(1 \%)$, $\mathrm{POP}-\mathrm{BiF}_{3}(5 \%)$, and $\mathrm{POP}-\mathrm{BiF}_{3}(10 \%)$ composite pellets revealed almost similar surfaces to the $\mathrm{POP}-\mathrm{BiF}_{3}(0 \%)$ pellet accompanied with several entangled random oriented rods forming the net-like porous structure. However, with the addition of $\mathrm{BiF}_{3}$ in the POP matrix, the porosity of the surface reduced in $\mathrm{POP}-\mathrm{BiF}_{3}(1 \%), \mathrm{POP}-\mathrm{BiF}_{3}(5 \%)$, and POP$\mathrm{BiF}_{3}(10 \%)$ composite pellets, relatively, as compared to the surface of the $\mathrm{POP}-\mathrm{BiF}_{3}(0 \%)$ pellet. The addition of $\mathrm{BiF}_{3}$ may have filled the pores of $\mathrm{POP}$ and, therefore, led to a smooth and glassy surface in the $\mathrm{POP}-\mathrm{BiF}_{3}(10 \%)$ composite pellet.

Further, to check the photocatalytic performance of $\mathrm{BiF}_{3}$ in the POP matrix, the $\mathrm{Rz}$ ink was prepared by using a known reported method [38]. Rz ink is an indicator of self-cleaning/photocatalysis, which changes its color if coated over any surface of photocatalytic material under the exposure of UV irradiation. Therefore, an equal amount of ink was pasted over each surface of $\mathrm{POP}-\mathrm{BiF}_{3}(0 \%), \mathrm{POP}-\mathrm{BiF}_{3}(1 \%), \mathrm{POP}-\mathrm{BiF}_{3}(5 \%)$, and POP- $-\mathrm{BiF}_{3}(10 \%)$ composite pellets. These pellets were subjected to UV light $(355 \mathrm{~nm})$ illumination with equal exposures and monitored with time on several fixed intervals for 180 min of time duration. Each time, surface images of $\mathrm{POP}_{-} \mathrm{BiF}_{3}(0 \%), \mathrm{POP}-\mathrm{BiF}_{3}(1 \%)$, 
POP- $-\mathrm{BiF}_{3}(5 \%)$, and $\mathrm{POP}-\mathrm{BiF}_{3}(10 \%)$ composite pellets were obtained via a high-quality digital camera. For comparison purposes, all captured images on certain time intervals were compiled together and shown in Figure 5 . In correlation to Figure $5, \Delta R G B^{\prime} t$ vs. time is plotted and shown as Figure 6a,b, which represents the change in blue as Figure 6a and change in red color as Figure $6 \mathrm{~b}$ due to photo-reduction in the Rz indicator ink under the UV light irradiation on $\mathrm{POP}-\mathrm{BiF}_{3}(\%)$ composites, respectively.

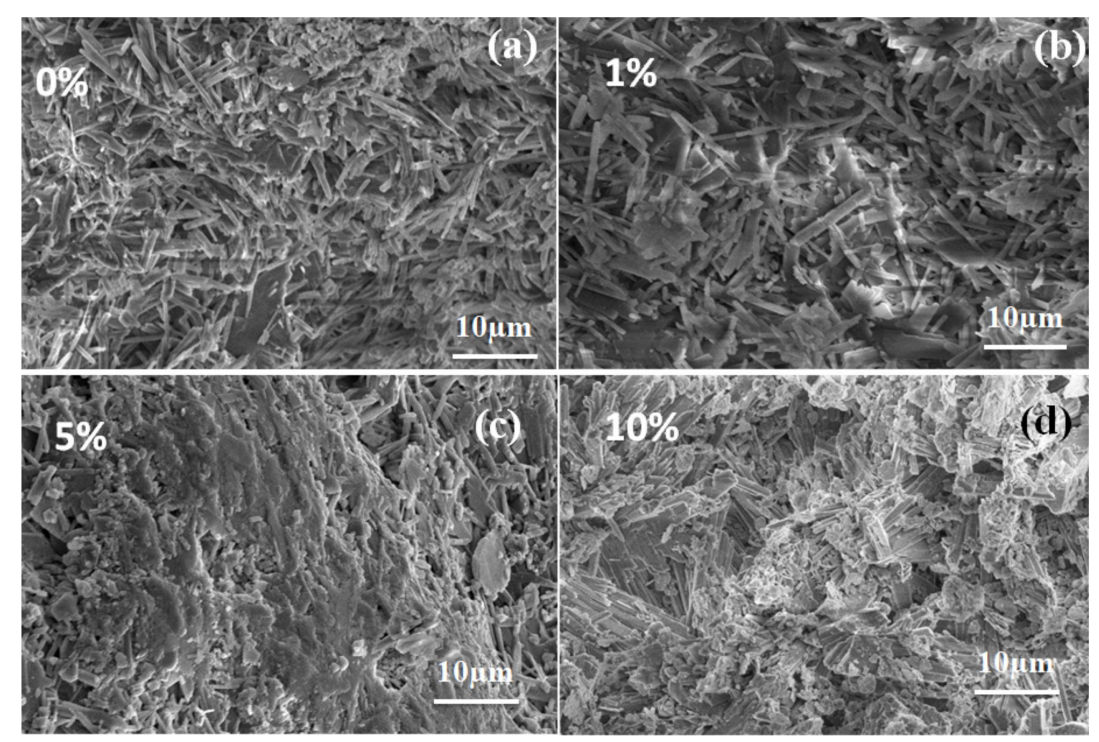

Figure 4. Typical SEM images of $\mathrm{POP}-\mathrm{BiF}_{3}(\%)$ composites along with the concentration variation of $\mathrm{BiF}_{3}$ for (a) $0 \%$, (b) $1 \%$, (c) $5 \%$, and (d) $10 \%$ in POP matrix.

Table 1. Comprehensive study of photocatalysis activity of $\mathrm{BiF}_{3}$ catalyst.

\begin{tabular}{|c|c|c|c|c|c|}
\hline Catalyst & Process & Pollutant & Power Source & Catalysis Time & Performance \\
\hline $\mathrm{BiOI} / \mathrm{BiF}_{3}$ composite [39] & Photocatalysis & $\begin{array}{l}\text { Tetracycline } \\
\text { hydrochloride }\end{array}$ & Visible light & $120 \mathrm{~min}$ & $\sim 75.6 \%$ \\
\hline $\mathrm{BiF}_{3}-\mathrm{Bi}_{2} \mathrm{NbO}_{5} \mathrm{~F}$ core - shell [34] & Photocatalysis & RB dye & Visible light & $90 \mathrm{~min}$ & $0.028 \mathrm{~min}^{-1}$ \\
\hline $\begin{array}{c}\mathrm{BiOCl} / \mathrm{BiF}_{3} \\
\text { heterojunction [40] }\end{array}$ & Photocatalysis & MO dye & $\begin{array}{l}\text { UV } \\
\text { light }\end{array}$ & $30 \mathrm{~min}$ & $\sim 90 \%$ \\
\hline $\mathrm{BiF}_{3}$ octahedrons [41] & Photocatalysis & RB dye & Solar light & $50 \mathrm{~min}$ & $\sim 95.7 \%$ \\
\hline $\mathrm{BiF}_{3}$ nanoparticles [32] & Photocatalysis & RB dye & UV light & $50 \mathrm{~min}$ & $\sim 78.5 \%$ \\
\hline $\mathrm{BiF}_{3} / \mathrm{BiOBr}$ heterojunctions [42] & Photocatalysis & MO dye & Visible light & $200 \min$ & $\sim 82.6 \%$ \\
\hline $\begin{array}{l}\text { Bismuth Fluoride Surface } \\
\text { Crystallized } 2 \mathrm{Bi}_{2} \mathrm{O}_{3}-\mathrm{B}_{2} \mathrm{O}_{3} \text { Glass [43] }\end{array}$ & Photocatalysis & Rhodamine 6G & Halogen lamp & $120 \mathrm{~min}$ & $\sim 85 \%$ \\
\hline $\begin{array}{c}\text { Bismuth Fluoride on } \\
\mathrm{SrO}-\mathrm{Bi}_{2} \mathrm{O}_{3}-\mathrm{B}_{2} \mathrm{O}_{3} \text { transparent Glass } \\
\text { ceramic }[44]\end{array}$ & Photocatalysis & MB dye & Visible lights & $540 \mathrm{~min}$ & $0.02226 \mathrm{~min}^{-1}$ \\
\hline $\begin{array}{l}\mathrm{BiOCl} / \mathrm{BiF}_{3} \text { on } \mathrm{ZnO}-\mathrm{Bi}_{2} \mathrm{O}_{3}-\mathrm{B}_{2} \mathrm{O}_{3} \\
\text { glass [45] }\end{array}$ & Photocatalysis & MB dye & UV light & $300 \mathrm{~min}$ & $\sim 90 \%$ \\
\hline $\mathrm{BiF}_{3}$ (present study) & Photocatalysis & MB dye & UV light & $120 \mathrm{~min}$ & $0.0103 \mathrm{~min}^{-1}$ \\
\hline
\end{tabular}




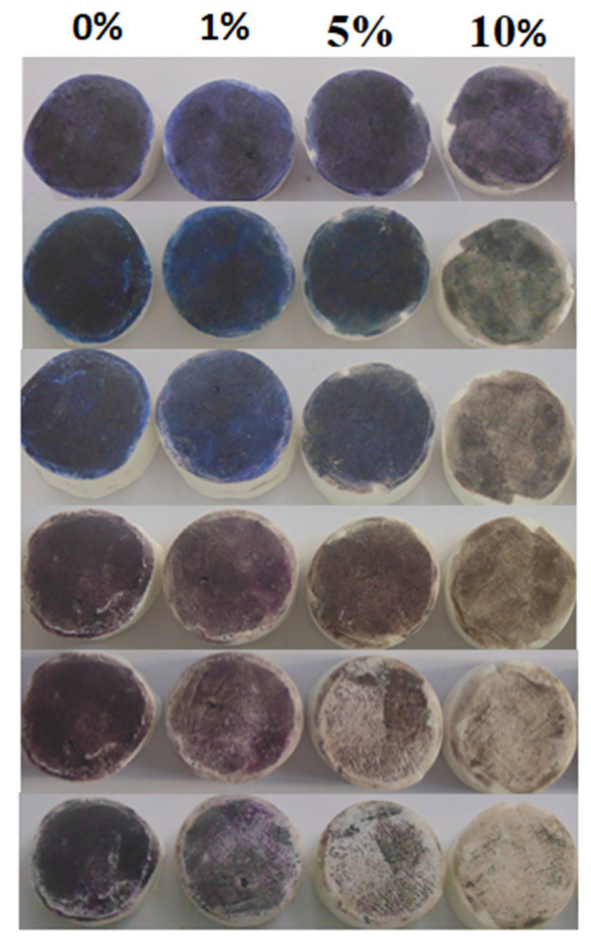

\section{0 min \\ $15 \min$ \\ $30 \mathrm{~min}$ \\ $60 \mathrm{~min}$ \\ $120 \mathrm{~min}$ \\ $180 \mathrm{~min}$}

Figure 5. Photo-reduction in $\mathrm{Rz}$ indicator ink for $3 \mathrm{~h}$ reaction timeline on $\mathrm{POP}-\mathrm{BiF}_{3}(\%)$ composites having the variation of $\mathrm{BiF}_{3} 0 \%, 1 \%, 5 \%$, and $10 \%$ by wt., respectively, under the exposure of $355 \mathrm{~nm}$ wavelength of UV light irradiation.

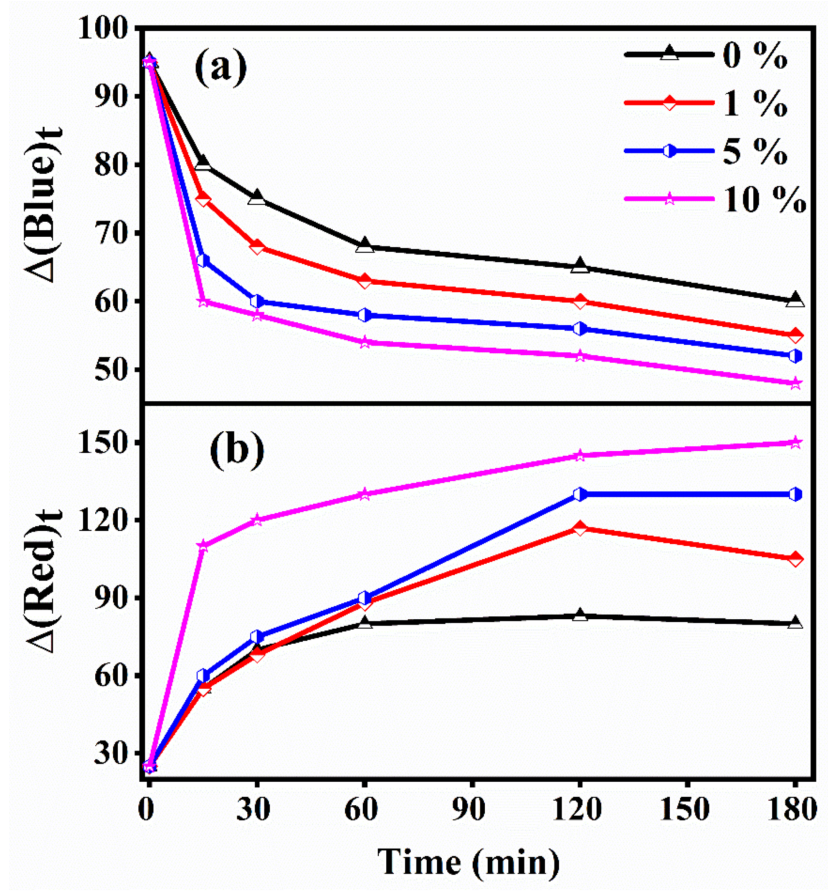

Figure 6. $\triangle \mathrm{RGB}^{\prime} \mathrm{t}$ vs. time plots for (a) blue and (b) red color change due to photo-reduction inRz indicator ink on $\mathrm{POP}-\mathrm{BiF}_{3}(\%)$ composites having $\mathrm{BiF}_{3} \mathrm{0} \%, 1 \%, 5 \%$, and $10 \%$ by wt., respectively, under the UV light irradiation.

In the present case, under the exposure of UV light on the POP- $\mathrm{BiF}_{3}(0 \%)$ composite pellet, which had no $\mathrm{BiF}_{3}$ content, showed no color change on the surface up to the $30 \mathrm{~min}$ of time duration, while a slight change after $60 \mathrm{~min}$ to $180 \mathrm{~min}$ was monitored. This slight change from a blue to purple color was due to the photolysis of the Rz ink. For POP- 
$\mathrm{BiF}_{3}(1 \%), \mathrm{POP}-\mathrm{BiF}_{3}(5 \%)$, and POP $-\mathrm{BiF}_{3}(10 \%)$ composite pellets, the color of the $\mathrm{Rz}$ ink readily changed in proportion to the $\mathrm{BiF}_{3}$ content in POP from royal blue to pink and then into colorless ink. The rate of change in the color of the $\mathrm{Rz}$ ink was systematic and increased for $\mathrm{POP}-\mathrm{BiF}_{3}(0 \%), \mathrm{POP}-\mathrm{BiF}_{3}(1 \%), \mathrm{POP}-\mathrm{BiF}_{3}(5 \%)$, and $\mathrm{POP}-\mathrm{BiF} \mathrm{F}_{3}(10 \%)$ composite pellets, respectively. The color of the $\mathrm{Rz}$ ink over the surface of the POP-BiF $3(10 \%)$ composite pellet appeared almost colorless within the $180 \mathrm{~min}$ time period.

Usually, the rate of the change of color of the Rz ink indicates the rate of photocatalytic reduction. The reaction mechanism of photocatalytic reduction and the color-change of the $\mathrm{Rz}$ ink are mentioned as under Equations (3)-(6).

$$
\begin{gathered}
\mathrm{BiF}_{3} \stackrel{h \vartheta}{\rightarrow} \mathrm{BiF}_{3}\left(e^{-}, h^{+}\right) \\
\text {Glycerol } \stackrel{h^{+}}{\rightarrow} \mathrm{OH}+\text { Glyceric acid } \\
\mathrm{BiF} F_{3} *\left(e^{-}, h^{+}\right) \rightarrow \mathrm{BiF}_{3}
\end{gathered}
$$

At the same time of the image capture, the POP $-\mathrm{BiF}_{3}(0 \%), \mathrm{POP}-\mathrm{BiF}_{3}(1 \%), \mathrm{POP}-$ $\mathrm{BiF}_{3}(5 \%)$, and $\mathrm{POP}-\mathrm{BiF}_{3}(10 \%)$ composite pellets were again tested through $\mathrm{UV}-$ visible spectroscopy for a quantitative analysis of the photocatalytic reduction in the $\mathrm{Rz}$ ink coated over the surfaces. Absorption peak intensities corresponding to the photo catalytic reduction were monitored at two different wavelengths, i.e., $630 \mathrm{~nm}$ and $581 \mathrm{~nm}$. The absorption spectra obtained from the UV-visible spectroscopy is illustrated in Figure 7a-d. The peak intensity monitored at the $630 \mathrm{~nm}$ wavelength directly correlated to the blue color of the $\mathrm{Rz}$ ink and with the exposure of UV light (355 nm). The peak intensity of absorbance decreased at the wavelength of $630 \mathrm{~nm}$ along with the color change from blue to pink, resulting in the formation of resorufin (Rf) as a byproduct. The intensity decay of another peak at $581 \mathrm{~nm}$ represented the photobleaching of the Rf molecule as and when the color changed from pink to colorless. Under the effect of UV light irradiation, a negligible change in the intensity of characteristic absorption of the Rz ink was observed for the $\mathrm{POP}-\mathrm{BiF}_{3}(0 \%)$ composite pellet; however, the absorption intensity of the Rz ink decreased consistently for all the other samples just in accordance with the color change observed in the digital photographs as shown in Figure 5. The absorption results are shown in Figure $7 \mathrm{a}-\mathrm{d}$ was further utilized to extract the kinetic rate of photocatalytic reduction and photo mineralization of intermediates of the $\mathrm{Rz}$ ink monitored for both the wavelengths at $630 \mathrm{~nm}$ and $581 \mathrm{~nm}$, respectively, shown in Figure 8. In Figure 8, Co represents the initial $(t=0)$ absorbance of the Rz ink and $C$ is the absorbance of the Rz ink, which varied with time $t$. The $C o$ and $C$ and kinetic rate of photocatalytic reduction was calculated corresponding to the absorption spectra monitored for both the wavelengths of absorbance, i.e., $581 \mathrm{~nm}$ and $630 \mathrm{~nm}$ of $\mathrm{Rz}$ ink. For the $\mathrm{POP}-\mathrm{BiF}_{3}(0 \%)$ sample, the results showed that the intensity decay, as well as the kinetic rate of reaction due to the photocatalytic degradation of the $\mathrm{Rz}$ ink corresponding to the wavelengths monitored at $581 \mathrm{~nm}$ and $630 \mathrm{~nm}$ for $180 \mathrm{~min}$ of time duration, was less. Generally, the photocatalytic reaction rate was monitored to correspond faster to the absorbance at $630 \mathrm{~nm}$ wavelengths in comparison to the absorbance around the $581 \mathrm{~nm}$ wavelength for all samples. As compared to POP$\mathrm{BiF}_{3}(0 \%)$, the POP $-\mathrm{BiF}_{3}(1 \%), \mathrm{POP}-\mathrm{BiF}_{3}(5 \%)$, and $\mathrm{POP}-\mathrm{BiF}_{3}(10 \%)$ composite pellets showed relatively faster kinetic rate of photocatalytic reduction in the $\mathrm{Rz}$ ink, respectively. 


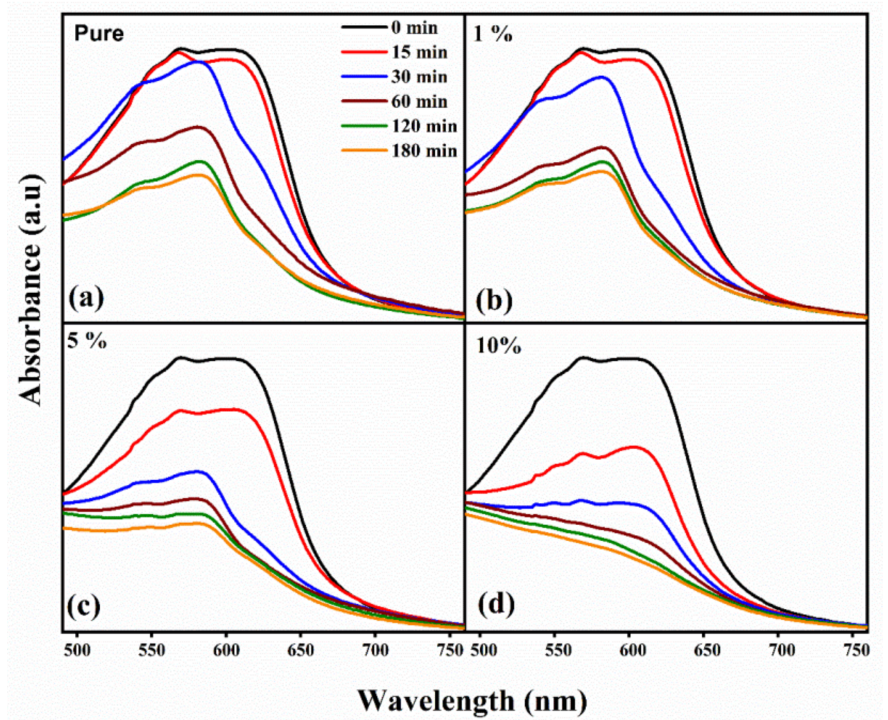

Figure 7. Absorption vs. wavelength spectra for the photocatalysis of Rz ink on the surface of POP- $-\mathrm{BiF}_{3}(\%)$ composites with the variation of $\mathrm{BiF}_{3}$ concentration $(\mathbf{a}) 0 \%$, (b) $1 \%$, (c) $5 \%$, and (d) $10 \%$ in POP matrix.
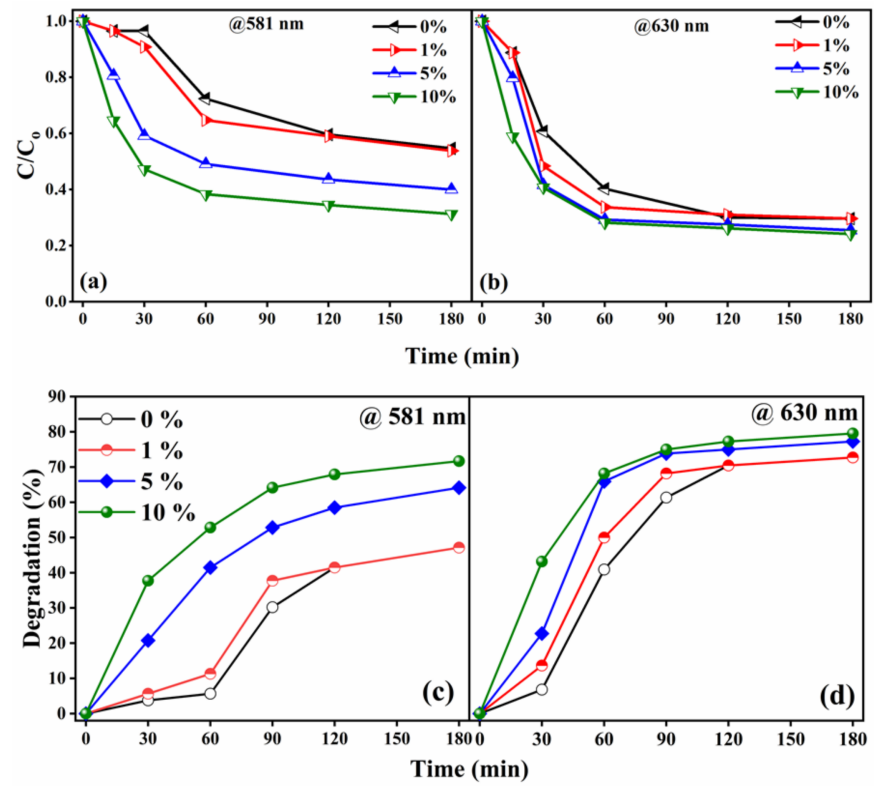

Figure 8. The $\mathrm{C} / \mathrm{Co}$ vs. time plots for photocatalytic degradation of $\mathrm{Rz}$ ink for $\mathrm{POP}-\mathrm{BiF}_{3}(\%)$ composites monitored at: (a) $581 \mathrm{~nm}$ and (b) $630 \mathrm{~nm}$ wavelength, and respective percentage of photocatalytic degradation for (c) $581 \mathrm{~nm}$ and (d) $630 \mathrm{~nm}$ wavelength.

For simplicity, the photoreduction due to UV light irradiation of Rz ink, which was coated on POP- $\mathrm{BiF}_{3}$ composite pellets, is shown in Figure 9. Under the illumination of UV light irradiation, the catalyst material $\mathrm{BiF}_{3}$ present in $\mathrm{POP}$ generated sacrificial donor electrons on its surface which reacted with the photo-induced holes of the Rz ink. Therefore, the glycerol present in the Rz ink utilized this sacrificial donor electron and generated an - $\mathrm{OH}$ radicle along with glyceric acid as a by-product. At the same time, these intermediate - $\mathrm{OH}$ radicles reduced the blue color of the Rz ink into Rf of the pink color after the longtime illumination of UV light irradiation, resulting in the reduction in the Rf molecule into a colorless product. Similar to the Rz ink, the harmful pollutants may have also reduced into non-harmful products with the aid of hydroxyl radicals generated on the surface of the photocatalytic $\mathrm{BiF}_{3}$ in the POP matrix. In the present work, we obtained a maximum 
content of $\mathrm{BiF}_{3}$ only up to $10 \%$ in the POP matrix. The Further addition of $\mathrm{BiF}_{3}$ in $\mathrm{POP}$ may have led to the decay in the mechanical strength of the architecture. The concentration of $\mathrm{BiF}_{3}$ inside the POP matrix along with an optimized photocatalytic performance and superior strength of the structures are a further matter of research. Thus, the above results demonstrate the successful photocatalytic application of $\mathrm{BiF}_{3}$ inside the POP matrix. POP is an important cementitious material used for the making of several building constructions and sculptures. We propose here for the addition of $\mathrm{BiF}_{3}$ as an activated photocatalytic material in the side of any cementitious material for self-cleaning of building constructions and a reduction in environmental pollution.

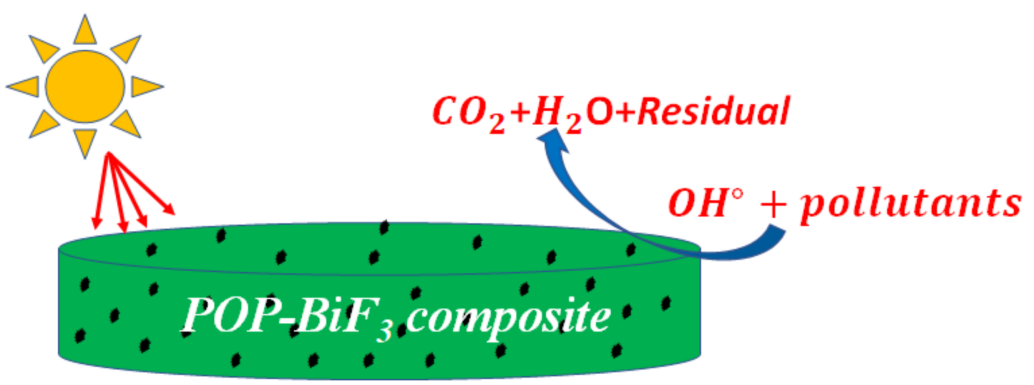

Figure 9. The schematic representation of the proposed mechanism for the photocatalytic degradation of pollutants under UVlight irradiation over $\mathrm{POP}-\mathrm{BiF}_{3}$ composite pellet surfaces.

\section{Conclusions}

Successfully, theBiF 3 powder sample was prepared via the precipitation route simply by washing the purchased powder of $\mathrm{Bi}_{2} \mathrm{O}_{3}$ several times into the concentrated $\mathrm{HF}$ solution. After several washes through the concentrated HF solution, the $\mathrm{Bi}_{2} \mathrm{O}_{3}$ powder was systematically transformed into $\mathrm{BiF}_{3}$ powder in conjunction with each washing. An intermediate phase of $\mathrm{Bi}_{1.2} \mathrm{~F}_{2.4} \mathrm{O}_{0.6}$ was identified for the 1 st and 2 nd washing of the $\mathrm{Bi}_{2} \mathrm{O}_{3}$ powder, which completely vanished after the 3 rd washing and converted into the $\mathrm{BiF}_{3}$ powder sample. The photocatalytic performance of the as-prepared $\mathrm{BiF}_{3}$ powder was tested and compared with the $\mathrm{Bi}_{2} \mathrm{O}_{3}$ powder on a hazardous industrial waste solution of $\mathrm{MB}$ dye. The $\mathrm{BiF}_{3}$ powder rapidly decomposed the $\mathrm{MB}$ solution under the visible light illumination as compared to the purchased $\mathrm{Bi}_{2} \mathrm{O}_{3}$ powder sample. Usually, POP is used vastly in the construction as well as the building of sculptures and, therefore, is always exposed to water as well as air pollutants. Therefore, to check the self-cleaning activity from such pollutants and introduce the photocatalytic properties in $\mathrm{POP}, \mathrm{BiF}_{3}$ powders were added according to $0 \%, 1 \%, 5 \%$, and $10 \%$ by wt $\%$ in the POP matrix. The photocatalytic and self-cleaning properties of these $\mathrm{POP}-\mathrm{BiF}_{3}$ composites were demonstrated by using a well-known photocatalysis indicator ink of $\mathrm{Rz}$ under visible light exposure. Due to the photocatalytic effect of $\mathrm{POP}-\mathrm{BiF}_{3}$ composites under the solar illumination, the blue color of the $\mathrm{Rz}$ ink turned into $\mathrm{Rf}$ of the pink color. The long-time illumination of visible light resulted from the reduction in the pink color Rf molecules into the colorless product. Photocatalytic performances were improved linearly for the incorporation of $\mathrm{BiF}_{3}$ up to $10 \%$ of the concentration in the POP matrix.

Author Contributions: Conceptualization, V.P.S. and R.V.; methodology, V.P.S., R.V., S.-H.P. and M.K.; validation, V.P.S., M.S. and D.M.; formal analysis, V.P.S., M.S. and D.M.; investigation, V.P.S., M.K., M.S. and D.M.; resources, R.V., K.-S.S. and S.-H.P.; data curation, V.P.S. and M.K.; writing, V.P.S., R.V., S.-H.P. and M.K.; writing-review and editing, V.P.S., R.V., S.-H.P. and M.K.; visualization, V.P.S., R.V., S.-H.P. and M.K.; supervision, R.V., K.-S.S. and S.-H.P.; project administration, R.V., K.-S.S. and S.-H.P.; funding acquisition, K.-S.S. and S.-H.P. All authors have read and agreed to the published version of the manuscript.

Funding: This work was supported by the 2021 Yeungnam University Research Grant. 
Acknowledgments: V. P. Singh and Rahul Vaish acknowledge the NPIU and AICTE for the CRS grant under the TEQIP III program for research-related work.RV thanks the CSIR, New Delhi, India, for the financial support under the sponsored research project scheme.

Conflicts of Interest: The authors declare no conflict of interest.

\section{References}

1. Li, J.; Yu, Y.; Zhang, L. Bismuth oxyhalide nanomaterials: Layered structures meet photocatalysis. Nanoscale 2014, 6, 8473-8488. [CrossRef]

2. Tian, G.; Chen, Y.; Zhou, W.; Pan, K.; Dong, Y.; Tian, C.; Fu, H. Facile solvothermal synthesis of hierarchical flower-like Bi $2 \mathrm{MoO}_{6}$ hollow spheres as high performance visible-light driven photocatalysts. J. Mater. Chem. 2011, 21, 887-892. [CrossRef]

3. Zhang, B.L.W.; Wang, Y.J.; Cheng, H.Y.; Yao, W.Q.; Zhu, Y.F. Synthesis of porous $\mathrm{Bi}_{2} \mathrm{WO}_{6}$ thin films as efficient visible-light-active photocatalysts. Adv. Mater. 2009, 21, 1286-1290. [CrossRef]

4. Li, R.; Zhang, F.; Wang, D.; Yang, J.; Li, M.; Zhu, J.; Zhou, X.; Han, H.; Li, C. Spatial separation of photogenerated electrons and holes among $\{010\}$ and $\{110\}$ crystal facets of $\mathrm{BiVO}_{4}$. Nat. Commun. 2013, 4, 1432. [CrossRef]

5. Wang, B.C.; Nisar, J.; Pathak, B.; Kang, T.W.; Ahuja, R. Band gap engineering in $\mathrm{BiNbO}_{4}$ for visible-light photocatalysis. Appl. Phys. Lett. 2012, 100, 182102. [CrossRef]

6. Shi, R.; Lin, J.; Wang, Y.; Xu, J.; Zhu, Y. Visible-light photocatalytic degradation of $\mathrm{BiTaO}_{4}$ photocatalyst and mechanism of photocorrosion suppression. J. Phys. Chem. C 2010, 114, 6472-6477. [CrossRef]

7. You, Q.; Fu, Y.; Ding, Z.; Wu, L.; Wang, X.; Li, Z. A facile hydrothermal method to BiSbO4 nanoplates with superior photocatalytic performance for benzene and 4-chlorophenol degradations. Dalton Trans. 2011, 40, 5774-5780. [CrossRef] [PubMed]

8. Wu, J.; Huang, F.; Lü, X.; Chen, P.; Wan, D.; Xu, F. Improved visible-light photocatalysis of nano- $\mathrm{Bi}_{2} \mathrm{Sn}_{2} \mathrm{O}_{7}$ with dispersed s-bands. J. Mater. Chem. 2011, 21, 3872-3876. [CrossRef]

9. Gao, F.; Chen, X.; Yin, K.; Dong, S.; Ren, Z.; Yuan, F.; Yu, T.; Zou, Z.G.; Liu, J.-M. Visible-light photocatalytic properties of weak magnetic $\mathrm{BiFeO}_{3}$ nanoparticles. Adv. Mater. 2007, 19, 2889-2892. [CrossRef]

10. Zhang, Q.; Gong, W.; Wang, J.; Ning, X.; Wang, Z.; Zhao, X.; Ren, W.; Zhang, Z. Size-dependent magnetic, photoabsorbing, and photocatalytic properties of single-crystalline $\mathrm{Bi}_{2} \mathrm{Fe}_{4} \mathrm{O}_{9}$ semiconductor nanocrystals. J. Phys. Chem. C 2011, 115, 25241-25246. [CrossRef]

11. Pan, C.; Zhu, Y. Size-controlled synthesis of $\mathrm{BiPO}_{4}$ nanocrystals for enhanced photocatalytic performance. J. Mater. Chem. 2011, 21, 4235-4241. [CrossRef]

12. Lin, X.; Huang, F.; Wang, W.; Shi, J. Photocatalytic activity of $\mathrm{Bi}_{24} \mathrm{Ga}_{2} \mathrm{O}_{39}$ for degrading methylene blue. Scr. Mater. 2007, 56, 189-192 [CrossRef]

13. Mohn, C.E.; Stølen, S. Influence of the stereochemically active bismuth lone pair structure on ferroelectricity and photocalytic activity of Aurivillius phase $\mathrm{Bi}_{2} \mathrm{WO}_{6}$. Phys. Rev. B Condens. Matter Mater. Phys. 2011, 83, 01410. [CrossRef]

14. Yu, C.; Yang, P.; Tie, L.; Yang, S.; Dong, S.; Sun, J.; Sun, J. One-pot fabrication of $\beta-\mathrm{Bi}_{2} \mathrm{O}_{3} @ \mathrm{Bi}_{2} \mathrm{~S}_{3}$ hierarchical hollow spheres with advanced sunlight photocatalytic RhB oxidation and Cr(VI) reduction activities. Appl. Surf. Sci. 2018, 455, 8-17. [CrossRef]

15. Yan, Q.; Xie, X.; Liu, Y.; Wang, S.; Zhang, M.; Chen, Y.; Si, Y. Constructing a new Z-scheme multi-heterojunction photocataslyts Ag-AgI/BiOI- $\mathrm{Bi}_{2} \mathrm{O}_{3}$ with enhanced photocatalytic activity. J. Hazard. Mater. 2019, 371, 304-315. [CrossRef] [PubMed]

16. Chen, L.; He, J.; Yuan, Q.; Liu, Y.; Au, C.T.; Yin, S.F. Environmentally benign synthesis of branched $\mathrm{Bi}_{2} \mathrm{O}_{3}-\mathrm{Bi}_{2} \mathrm{~S}_{3}$ photocatalysts by an etching and re-growth method. J. Mater. Chem. A 2015, 3, 1096-1102. [CrossRef]

17. Zou, S.; Teng, F.; Chang, C.; Liu, Z.; Wang, S. Controllable synthesis of uniform BiOF nanosheets and their improved photocatalytic activity by an exposed high-energy (002) facet and internal electric field. RSC Adv. 2015, 5, 88936-88942. [CrossRef]

18. Lu, H.; Hao, Q.; Chen, T.; Zhang, L.; Chen, D.; Ma, C.; Yao, W.; Zhu, Y. A high-performance $\mathrm{Bi}_{2} \mathrm{O}_{3} / \mathrm{Bi}_{2} \mathrm{SiO}_{5}$ p-n heterojunction photocatalyst induced by phase transition of $\mathrm{Bi}_{2} \mathrm{O}_{3}$. Appl. Catal. B Environ. 2018, 237, 59-67. [CrossRef]

19. Bian, Z.; Zhu, J.; Wang, S.; Cao, Y.; Qian, X.; Li, H. Self-Assembly of Active $\mathrm{Bi}_{2} \mathrm{O}_{3} / \mathrm{TiO}_{2}$ Visible Photocatalyst with Ordered Mesoporous Structure and Highly Crystallized Anatase. J. Phys. Chem. C 2008, 112, 6258-6262. [CrossRef]

20. Hameed, A.; Montini, T.; Gombac, V.; Fornasiero, P. Surface phases and photocatalytic activity correlation of $\mathrm{Bi}_{2} \mathrm{O}_{3} / \mathrm{Bi}_{2} \mathrm{O}_{4-x}$ nanocomposite. J. Am. Chem. Soc. 2008, 130, 9658-9659. [CrossRef]

21. Brezesinski, K.; Ostermann, R.; Hartmann, P.; Perlich, J.; Brezesinski, T. Exceptional photocatalytic activity of ordered mesoporous $\beta-\mathrm{Bi}_{2} \mathrm{O}_{3}$ thin films and electrospun nanofiber mats. Chem. Mater. 2010, 22, 3079-3085. [CrossRef]

22. Dai, Y.; Yin, L. Synthesis and photocatalytic activity of Ag-Ti-Si ternary modified $\alpha-\mathrm{Bi}_{2} \mathrm{O}_{3}$ nanoporous spheres. Mater. Lett. 2015, 142, 225-228. [CrossRef]

23. Naik, B.; Parida, K.M.; Behera, G.C. Facile synthesis of $\mathrm{Bi}_{2} \mathrm{O}_{3} / \mathrm{TiO}_{2-\mathrm{x}} \mathrm{N}_{\mathrm{x}}$ and its direct solar-light-driven photocatalytic selective hydroxylation of phenol. Chem CatChem 2011, 3, 311-318. [CrossRef]

24. Yin, L.; Niu, J.; Shen, Z.; Chen, J. Mechanism of reductive decomposition of pentachlorophenol by ti-doped $\beta$ - $\mathrm{Bi}_{2} \mathrm{O}_{3}$ under visible light irradiation. Environ. Sci. Technol. 2010, 44, 5581-5586. [CrossRef] [PubMed]

25. Zhao, W.; Zhang, J.; Zhu, F.; Mu, F.; Zhang, L.; Dai, B.; Xu, J.; Zhu, A.; Sun, C.; Leung, D.Y. Study the photocatalytic mechanism of the novel $\mathrm{Ag} / \mathrm{p}-\mathrm{Ag}_{2} \mathrm{O} / \mathrm{n}-\mathrm{BiVO}_{4}$ plasmonic photocatalyst for the simultaneous removal of BPA and chromium(VI). Chem. Eng. J. 2019, 361, 1352-1362. [CrossRef] 
26. Habibi, Y.A.; Mousavi, M.; Nakata, K. Boosting visible-light photocatalytic performance of g- $\mathrm{C}_{3} \mathrm{~N}_{4} / \mathrm{Fe}_{3} \mathrm{O}_{4}$ anchored with $\mathrm{CoMoO}_{4}$ nanoparticles: Novel magnetically recoverable photocatalysts. J. Photochem. Photobiol. A Chem. 2019, 368, 120-136. [CrossRef]

27. Habibi, Y.A.; Mousavi, M. Deposition of $\mathrm{CuWO}_{4}$ nanoparticles over g- $\mathrm{C}_{3} \mathrm{~N}_{4} / \mathrm{Fe}_{3} \mathrm{O}_{4}$ nanocomposite: Novel magnetic photocatalysts with drastically enhanced performance under visible-light. Adv. Powder Technol. 2018, 29, 1379-1392. [CrossRef]

28. Mousavi, M.; Habibi, Y.A.; Pouran, S.R. Review on magnetically separable graphitic carbon nitride-based nanocomposites as promising visible-light-driven photocatalysts. J. Mater. Sci. Mater. Electron. 2018, 29, 1719-1747. [CrossRef]

29. Singh, V.P.; Mishra, D.; Kabachkov, E.N.; Shul'ga, Y.M.; Vaish, R. The characteristics of BiOCl/Plaster of Paris composites and their photocatalytic performance under visible light illumination for self-cleaning. Mater. Sci. Energy Technol. 2020, 3, $299-307$. [CrossRef]

30. Singh, V.P.; Vaish, R. Hierarchical growth of $\mathrm{BiOCl}$ on $\mathrm{SrO}-\mathrm{Bi}_{2} \mathrm{O}_{3}-\mathrm{B}_{2} \mathrm{O}_{3}$ glass-ceramics for self-cleaning applications. J. Am. Ceram. Soc. 2018, 101, 2901-2913. [CrossRef]

31. Zhao, J.; Pan, H.; He, X.; Wang, Y.; Gu, L.; Hu, Y.S.; Chen, L.; Liu, H.; Dai, S. Size-controlled synthesis and morphology evolution of bismuth trifluoride nanocrystals via a novel solvent extraction route. Nanoscale 2013, 5, 518-522. [CrossRef]

32. Feng, C.; Teng, F.; Liu, Z.; Chang, C.; Zhao, Y.; Wang, S.; Chen, M.; Yao, W.; Zhu, Y. A newly discovered BiF 3 photocatalyst with a high positive valence band. J. Mol. Catal. A Chem. 2015, 401, 35-40. [CrossRef]

33. Yang, Z.; Wang, X.; Liu, L.; Yang, S.; Su, X. First-principles calculations on structural, magnetic and electronic properties of oxygen doped $\mathrm{BiF}_{3}$. Comput. Mater. Sci. 2011, 50, 3131-3135. [CrossRef]

34. Lei, S.; Wang, C.; Cheng, D.; Gao, X.; Chen, L.; Yan, Y.; Zhou, J.; Xiao, Y.; Cheng, B. Hierarchical BiF ${ }_{3}-\mathrm{Bi}_{2} \mathrm{NbO}_{5} \mathrm{~F}$ core-shell structure and its application in the photosensitized degradation of rhodamine B under visible light irradiation. J. Phys. Chem. C 2015, 119, 502-511. [CrossRef]

35. Sarkar, S.; Dash, A.; Mahalingam, V. Strong stokes and upconversion luminescence from ultrasmall $\mathrm{Ln}^{3+}-\mathrm{doped} \mathrm{BiF}_{3}\left(\mathrm{Ln}^{2} \mathrm{Eu}^{3+}\right.$, $\left.\mathrm{Yb}^{3+} / \mathrm{Er}^{3+}\right)$ nanoparticles confined in a polymer matrix. Chem. Asian J. 2014, 9, 447-451. [CrossRef] [PubMed]

36. Kan, Y.; Teng, F.; Yang, Y.; Xu, J.; Yang, L. Direct conversion mechanism from BiOCl nanosheets to $\mathrm{BiOF}_{1} \mathrm{Bi}_{7} \mathrm{~F}_{11} \mathrm{O}_{5}$ and $\mathrm{BiF}_{3}$ in the presence of a fluorine resource. RSC Adv. 2016, 6, 63347-63357. [CrossRef]

37. Yu, J.; Li, C.; Liu, S. Effect of PSS on morphology and optical properties of ZnO. J. Colloid Interface Sci. 2008, 326, 433-438. [CrossRef] [PubMed]

38. Mills, A.; Wang, J.; McGrady, M. Method of rapid assessment of photocatalytic activities of self-cleaning films. J. Phys. Chem. B 2006, 110, 18324-18331. [CrossRef] [PubMed]

39. Lu, H.; Ju, T.; She, H.; Wang, L.; Wang, Q. Microwave-assisted synthesis and characterization of BiOI/ $\mathrm{BiF}_{3} \mathrm{p}-\mathrm{n}$ heterojunctions and its enhanced photocatalytic properties. J. Mater. Sci. Mater. Electron. 2020, 31, 13787-13795. [CrossRef]

40. Yang, Y.; Teng, F.; Kan, Y.; Yang, L.; Liu, Z.; Gu, W.; Zhang, A.; Hao, W.; Teng, Y. Investigation of the charges separation and transfer behavior of BiOCl/BiF3heterojunction. Appl. Catal. B Environ. 2017, 205, 412-420. [CrossRef]

41. Ritika; Kaur, M.; Umar, A.; Mehta, S.K.; Kansal, S.K. BiF 3 octahedrons: A potential natural solar light active photocatalyst for the degradation of Rhodamine B dye in aqueous phase. Mater. Res. Bull. 2019, 112, 376-383. [CrossRef]

42. Zhang, S.; Chen, X.; Song, L. Preparation of $\mathrm{BiF}_{3} / \mathrm{BiOBr}$ heterojunctions from microwave-assisted method and photocatalytic performances. J. Hazard. Mater. 2019, 367, 304-315. [CrossRef] [PubMed]

43. Sharma, S.K.; Singh, V.P.; Chauhan, V.S.; Kushwaha, H.S.; Vaish, R. Photocatalytic Active Bismuth Fluoride/Oxyfluoride Surface Crystallized $2 \mathrm{Bi}_{2} \mathrm{O}_{3}-\mathrm{B}_{2} \mathrm{O}_{3}$ Glass-Ceramics. J. Electron. Mater. 2018, 47, 3490-3496. [CrossRef]

44. Singh, V.P.; Vaish, R. Controlled crystallization of photocatalytic active Bismuth oxyfluoride/ $\mathrm{Bismuth}$ fluoride on $\mathrm{SrO}_{-} \mathrm{Bi}_{2} \mathrm{O}_{3}-$ $\mathrm{B}_{2} \mathrm{O}_{3}$ transparent glass ceramic. J. Eur. Ceram. Soc. 2018, 38, 3635-3642. [CrossRef]

45. Singh, G.; Singh, V.P.; Vaish, R. Controlled crystallization of $\mathrm{BiOCl} / \mathrm{BiF}{ }_{3}$ on $\mathrm{ZnO}-\mathrm{Bi}_{2} \mathrm{O}_{3}-\mathrm{B}_{2} \mathrm{O}_{3}$ glass surfaces for photocatalytic and self-cleaning applications. Materialia 2019, 5, 100196. [CrossRef] 